\title{
Sociocultural Context and Determinants of Treatments for Hemorrhoids Among the Nigeria Police Force, Oyo State Command
}

\author{
Abolaji Azeez \\ University of Ibadan \\ Uche C. Isiugo-Abanihe \\ University of Ibadan
}

Hemorrhoids or piles, culturally known as Jedijedi among the people of southwestern Nigeria, are an anorectal disease surrounded by misconceptions. The consequences of these misconceptions are enormous. Therefore, the main objective of the present study is to understand the sociocultural explanation of piles among selected personnel of the Nigeria Police Force. We recruited 302 police officers for the exploratory survey through a multistage sampling technique. Five key informants were interviewed at the study area based upon their professions and proximity. Data interpretation was done through chi-square and content analysis. Results indicated a high prevalence (73\%) of and misconceptions about hemorrhoids among the respondents. The majority (80\%) of the respondents had a poor awareness of the risk factors, making a scientifically unfounded claim that sugar intake was responsible for piles. Their belief negatively influenced the treatments adopted.

Furthermore, their choice of therapy was influenced by its affordability $(p<.05)$ and the fear of hemorrhoidectomy $(p<.05)$. The study established various misconceptions about hemorrhoids among herbal vendors and police officers, which influenced treatment choices. The study suggested that one potent tool for combating ignorance about the disease is sensitization, which will equip officers to adopt healthier behaviors and aid herbal vendors to give better treatment to their clients. In addition, experimental platforms should be set for herbal vendors and orthodox medical practitioners to form a synergy in combating the diseases.

Keywords: hemorrhoids, Jedijedi, hemorrhoidectomy, sexual problem, sugar intake

\section{Introduction}

Hemorrhoids (also known as piles), a common anorectal disease, is a varicose and often inflamed or swollen condition of the veins, inside or just outside the rectum, caused by increased pressure in the rectal veins, which displace the anal cushions (Lohsiriwat, 2013; Lohsiriwat, 2012). Biologically, it is a natural part of and functional in the human anatomy. Piles affect millions of people around the world and represent a major medical and socioeconomic problem (Lohsiriwat, 2012). Globally, it is

Please address queries to: Abolaji Azeez, Department of Sociology, Faculty of The Social Sciences, University of Ibadan, Nigeria. Email: abolaji2000@gmail.com

The survey was conducted with the financial support of the Council for the Development of Social Science Research in Africa (CODESRIA; SGRT.45/T13). We wish to thank the three anonymous reviewers for several useful contributions that were incorporated into this manuscript. We thank K. K. Salami, PhD; E. E. Nwokocha, PhD; and U. A. Ojedokun, PhD, for their constructive suggestions to the manuscript. 
difficult to ascertain its true prevalence (Lee, Kim, Kang, Shin, \& Song, 2014). The prevalence is yet to be studied, but it is estimated that at some point in their lives, the disease will affect $50 \%$ to $85 \%$ of the world's population (Omole \& Adegboye, 2012). In Africa as well, there is dearth of such data. Specifically, Nigeria is not exempt from the lack of comprehensive epidemiological data, even though hemorrhoids, as a disease, are included in Standard Treatment Guidelines (Federal Ministry of Health, 2008). Hemorrhoids are commonly known as Jedijedi in southwestern Nigeria (Osungunna, Oluremi, \& Talabi, 2010), especially when they become abnormal and unmanageable. Hemorrhoids manifest internally, externally (Lohsiriwat, 2015) or both simultaneously. The symptoms include painful defecation, bleeding, bloodstain on stool, and a feeling of incomplete defecation.

In Nigeria, the incidence and prevalence of hemorrhoids may not be known (Omole \& Adegboye, 2012), yet it is a common health challenge which affects quality of life (Sun \& Migaly 2016). The concept of piles has entered into the Yoruba sociolinguistic cultural tradition. Olateju (2009) explained how local herb dealers advertised their herbal remedy for hemorrhoids. These advertisements suggest that hemorrhoids are prevalent and that they can affect anyone in the community.

However, there are many misconceptions about the disease, because the exact pathophysiology of hemorrhoids is poorly understood (Lohsiriwat, 2015). In essence, many patients refuse surgical options because of their reservations about general anesthesia (Alatise, Agbakwuru, Takure, Adisa, \& Akinkuolie, 2010). Omole and Adegboye (2012) reported the poor state of hemorrhoids treatment in Nigeria. Also, there are many treatments for hemorrhoids. These include change in dietary and stooling habits and different surgical interventions (Hemorrhoid Institute of South Texas, 2009). The different philosophies of hemorrhoids development may lead to different approaches to the treatment of hemorrhoids (Lohsiriwat, 2012). Similarly, Soladoye, Chukwuma, and Owa (2012) identified some plants that are used to treat diseases such as hemorrhoids, cancer, and diabetes mellitus.

Interestingly, many individuals suffer from the condition without seeking medical consultation. Typically, patients are reluctant to seek medical help because of the embarrassment, fear, discomfort, and pain associated with the treatment (Kaidar-Person, Benjamin, \& Steven, 2007). Consequently, the exact incidence of this disease is difficult to estimate. Based on experience, Cleator and Cleator (2010) asserted that hemorrhoids are a common cause of distress and their treatment is often unsatisfactory due to recurrence or complications. This necessitates the need to ascertain the social and economic cost incurred during hemorrhoidal episodes.

Culturally, the definition given to a specific health challenge is borne out of the cultural world view, which is usually interpretatively relative. That is why both social activities and cultural practices do have causal effect on health. Erinosho (1998) and Gureje, Lasebikan, Olusola, Benjamin, and Lola (2005) categorized disease causations from sociocultural perspective as natural (biological), preternatural, and supernatural. In addition, Jegede (2010) added heredity to the existing causal factors. Generally, an individual's worldview is influenced by their internalized cultural values, norms, and beliefs system. The worldview in turn influences how individuals see the world and interpret their experiences. Against this backdrop, the study examined the knowledge of personnel of the Nigeria Police Force about the risk factors for hemorrhoids.

Perception of hemorrhoids can explain how worldview influences knowledge of its causes and effects. For example, Olateju (2009) reported that herbal vendors believed that symptoms of Jedijedi (hemorrhoids) in women include black, odorous, irregular, or hindered menstrual flow. Other symptoms include bloodstained stool, frequent stooling repeatedly, burning anus, painful bowel movement, and noisy anus. Hemorrhoids are believed to cut across all demographics: age, sex, social 
class, or status. Herbal vendors portray symptoms of hemorrhoids as inexhaustible. This has economic benefits for herbal vendors. All these are developed in the Yoruba cultural thoughts.

The Yoruba cultural tradition has identified the effects of hemorrhoids. The ailment has been perceived to be responsible for poor libido in women and weak erection in men prior to or during sexual episodes. This could be seen as impotence in men, which carries a social stigma (Olateju, 2009). Therefore, the health-seeking behavior that is exhibited as a result is culturally influenced. In social action theory, Weber (1991) maintained that instrumental actions entail those that are planned and taken after evaluating the goal in relation to other goals and after thorough consideration of various means (and consequences) to achieve it. Basically, patients (officers) suffering from hemorrhoids use herbal treatments. Expectedly, herbal medicine has enjoyed unprecedented patronage in southwestern Nigeria among the patients with hemorrhoids (Osungunna et al., 2010). Therefore, it is germane to understand the views of the orthodox and traditional practitioners in the treatment of hemorrhoids.

\section{Research Questions}

The research questions addressed by this study are the following:

Research Question 1: What is the perception about hemorrhoids in the study population?

Research Question 2: What are the factors that influence choice of therapy for hemorrhoid treatment?

\section{Method}

\section{Study Area}

The study was conducted among Nigeria Police Force personnel of the Oyo State Chapter, Southwest Nigeria. The study comprised the four areas of commands in Oyo State, namely Agodi, Iyaganku, Oyo, and Ogbomoso. The Nigeria Police Force performs conventional police functions and is responsible for internal security generally, for supporting the prison, immigration, and customs services; and for performing military duties within or outside Nigeria. Police officers were selected for this study since they are expected to maintain psychological and physiological homeostasis during numerous stressful activities. These activities, which include standing and sitting for a long period as well as walking continuously (Department of Public Safety Standards and Training, 2011), can predispose the police officers to hemorrhoids. Omole and Adegboye (2012) have noted that occupation involving severe muscular stress and prolonged standing and sitting are believed to increase susceptibility to hemorrhoids. Also, three herbal vendors and two medical practitioners in the study areas were recruited into the study. The selection of herbal vendors was based on high patronage of piles herbs and their experience in the business, whereas the medical practitioners at the Oyo State police medical centers were selected because they provide medical care for officers. These categories of respondents were expected to have better understanding of the issues under study. 


\section{Field Procedures}

This cross-sectional research design employed a multi-stage sampling procedure and a mixed methods approach. For quantitative aspect, a questionnaire was used to retrieve comprehensive information on hemorrhoids from the police officers. However, to gain complementary insights into treatments of piles from both orthodox and traditional practitioners, a qualitative method was employed. Essentially, the mixed method was utilized to capture holistic description of the phenomenon. Quantitative data provided information at micro level relating to misconception about the disease, preferred treatment and pathways to health. From macro perspective, qualitative data explained issues such as lifestyle, predisposing factors, timing, cultural diagnosis and delayed treatment of the disease. The descriptive data from the police coupled with the qualitative insights from orthodox and traditional practitioners provide comprehensive information on the subject matter.

For the quantitative category, the sample size was drawn from the population of police officers using Kish (1965) sample size formula:

$$
n=\frac{Z^{2} P(1-P)}{d^{2}}
$$

Where $n$ is the sample size; $Z$ is the $Z$ statistic for level of confidence at two-sided test (here, $Z=$ 1.96); $P$ is the expected prevalence or proportion for piles, which is 0.67 (Omole and Adegboye, 2012); and $d$ is precision, which is 0.05 here.

$$
n=\frac{(1.96)^{2}(0.67)(0.33)}{0.05^{2}}
$$

Therefore, $n=340$. With the nonresponse rate of $10 \%, 34$ copies of the questionnaire were added to 340 , making a total number of 374 respondents.

The permission to conduct the study was sought from the Oyo State Police Command Headquarters Eleyele in Ibadan. Four area commanders from the Oyo State Command were visited, and they gave the permission to conduct the research within their jurisdictions. At the divisional level, selected police stations in the Iyaganku and Agodi area commands were visited. However, because the Oyo and Ogbomoso area commands are widely dispersed, copies of the questionnaire were mailed to officers to complete through the administrative channels.

The administration and collection of the questionnaire were achieved through the help of the divisional police officers and the station officers. Informed consent of the officers were sought and received. In addition, anonymity of participating officers and confidentiality of the information received were guaranteed. Consequently, the measures encouraged the participants to return filled questionnaires to their respective divisional police officers or station officers as required. The administration of the questionnaires and collection of data took an approximately 10 weeks. Data from 302 respondents were used for the analysis. The remaining 72 copies of the questionnaires were either unfilled or incompletely filled.

For the qualitative data, five key informants were interviewed including three herbal vendors from Ibadan, Ogbomosho, and Oyo town. The interviews were conducted in the Yoruba language after herbal vendors gave their consents for the exercise. Also, two physicians from the Nigeria Police 
Force Medical Centre Oyo State Command were interviewed, one each from the Ibadan and Ogbomosho medical centers. All activities involved in data collection took 10 weeks; the data collection was carried out concurrently.

For the purpose of analysis, quantitative data were edited and cleaned to eliminate inconsistencies that could undermine validity. These data were finally analyzed with SPSS Version 21. A descriptive analysis of data was undertaken using univariate frequency distribution and cross-tabulation of variables, whose associated influence impact strongly on the study. Responses to statement on officers' perception of the effect of hemorrhoids on sexual activities and work were rated as 5 (strongly agree), 4 (agree), 3 (indifferent), 2 (disagree), or 1 (strongly disagree), with mean score of 3. Hence, a mean score above 3 points indicated that respondents agreed with the statement, whereas a mean score below 3 showed a disagreement with the statement.

The qualitative data were analyzed using ATLAS.ti 6.2. The process began with transcription and translation of computer recordings of the key informant interviews. The next stage involved coding of response relevant to the objective of the study. The program facilitated easy retrieval of quotes relevant to the study.

\section{Results}

\section{Sociodemographic Profiles of the Respondents}

In all, $67 \%$ of the respondents were male. The predominance of male officers in the sample is explained by the fact that the Nigeria Police Force is dominated by male officers. The mean age was 34 (range 20-69 years). A large majority (78\%) of the respondents were married, whereas $20 \%$ were reportedly single. The majority of the respondents have conjugal partners. Table 1 shows that the majority (74.8\%) of the respondents were Christians; $23.5 \%$ were Muslims. The table indicates that less than half (46.7\%) of the police respondents had either a Nigeria Certificate in Education or an Ordinary National Diploma.

Nearly $23 \%$ of the respondents had a secondary school degree or its equivalents, whereas only $1.7 \%$ had postgraduate degrees. Expectedly, a large majority (82\%) of the respondents were of Yoruba extraction, considering that Oyo State is predominantly inhabited by the Yoruba. The Igbo and the Hausa officers constituted $11 \%$ and $6 \%$ of the respondents, respectively.

The table further details the rank of the respondents. The highest number (41.4\%) was of the rank of corporal, followed by constables with $21 \%$. Officers in the position of inspector and sergeant constituted $13.2 \%$ and $13.8 \%$, respectively. Only a few officers belonged to the senior cadre of the Nigeria Police Force. The distribution by rank depicts a pyramidal structure of the Nigeria Police Force. With respect to respondents' illness experience, about $73.5 \%$ of police respondents had ever experienced hemorrhoids. This represents a high level of hemorrhoid prevalence in the study population. 
Table 1: Selected Sociodemographic Characteristics of the Respondents

\begin{tabular}{|c|c|c|}
\hline Characteristics & Frequency & Percent \\
\hline \multicolumn{3}{|l|}{ Sex } \\
\hline Male & 203 & 67.2 \\
\hline Female & 99 & 32.8 \\
\hline \multicolumn{3}{|l|}{ Age, years } \\
\hline $20-29$ & 89 & 29.50 \\
\hline $30-39$ & 135 & 44.70 \\
\hline $40-49$ & 57 & 18.90 \\
\hline $50-59$ & 20 & 6.6 \\
\hline $60-69$ & 1 & 0.30 \\
\hline \multicolumn{3}{|l|}{ Marital status } \\
\hline Married & 236 & 78.1 \\
\hline Single & 63 & 20.9 \\
\hline Divorced & 2 & 0.7 \\
\hline Cohabit & 1 & 0.3 \\
\hline \multicolumn{3}{|l|}{ Religious affiliations } \\
\hline Christianity & 226 & 74.8 \\
\hline Islam & 71 & 23.5 \\
\hline Indigenous religious & 5 & 1.7 \\
\hline \multicolumn{3}{|l|}{ Educational level } \\
\hline Primary & 3 & 1.0 \\
\hline Secondary & 84 & 27.8 \\
\hline NCE/OND & 141 & 46.7 \\
\hline HND/BSc & 69 & 22.8 \\
\hline $\mathrm{MSc} / \mathrm{PhD}$ & 5 & 1.7 \\
\hline \multicolumn{3}{|l|}{ Ethnic group } \\
\hline Hausa & 20 & 6.6 \\
\hline Igbo & 35 & 11.6 \\
\hline Yoruba & 247 & 81.8 \\
\hline \multicolumn{3}{|l|}{ Ranks } \\
\hline $\begin{array}{l}\text { Chief superintendent of } \\
\text { police }\end{array}$ & 2 & 0.7 \\
\hline Superintendent of police & 6 & 2.0 \\
\hline $\begin{array}{l}\text { Deputy superintendent of } \\
\text { police }\end{array}$ & 5 & 1.7 \\
\hline $\begin{array}{l}\text { Assistant superintendent of } \\
\text { police }\end{array}$ & 12 & 4.2 \\
\hline Inspector & 40 & 13.2 \\
\hline Sergeant & 42 & 13.8 \\
\hline Corporal & 125 & 41.4 \\
\hline Constable & 64 & 21.0 \\
\hline Undisclosed & 6 & 2.0 \\
\hline Total & 302 & 100 \\
\hline
\end{tabular}




\section{Perceived Risk Factors of Hemorrhoids}

Figure 1 presents respondents' perception of the causes of piles. The overwhelming majority (80\%) of the respondents believed that substances such as sugar, starch, oil, meat, beverages, and sex caused piles. A few (4\%) of the respondents correctly reported that the causes of piles are constipation, sitting and standing for long, a sedentary lifestyle, and low fiber intake. About 9\% of the respondents accepted both the correct and incorrect causes of piles at the same time. Accordingly, the results suggest that there is widespread misconception about the risk factors of hemorrhoids. The misconception among the police officers (80\%) in Figure 1 corroborates the views of all herbal vendors. The list of factors responsible for pile according to herbal vendors is broader than that of the officers. The excerpt below vividly captured consensual thoughts of the herbal vendors about the causes of hemorrhoids:

Many things cause piles; all foods especially solid ones, high carbohydrate concentration. In our place when people want to take pap they add sugar and pap itself contains a lot of carbohydrate. Even when some people cook yam they add sugar to it... The love and continuous consumption of red meat and rich tea is good for body but causes piles. (key informant interview [KII].d, female herbal vendor, Agbowo, Ibadan)

This quotation exemplifies the general cultural misconception that exists among patients and their herbal vendors who claimed to understand the etiology of hemorrhoids and how to treat it.

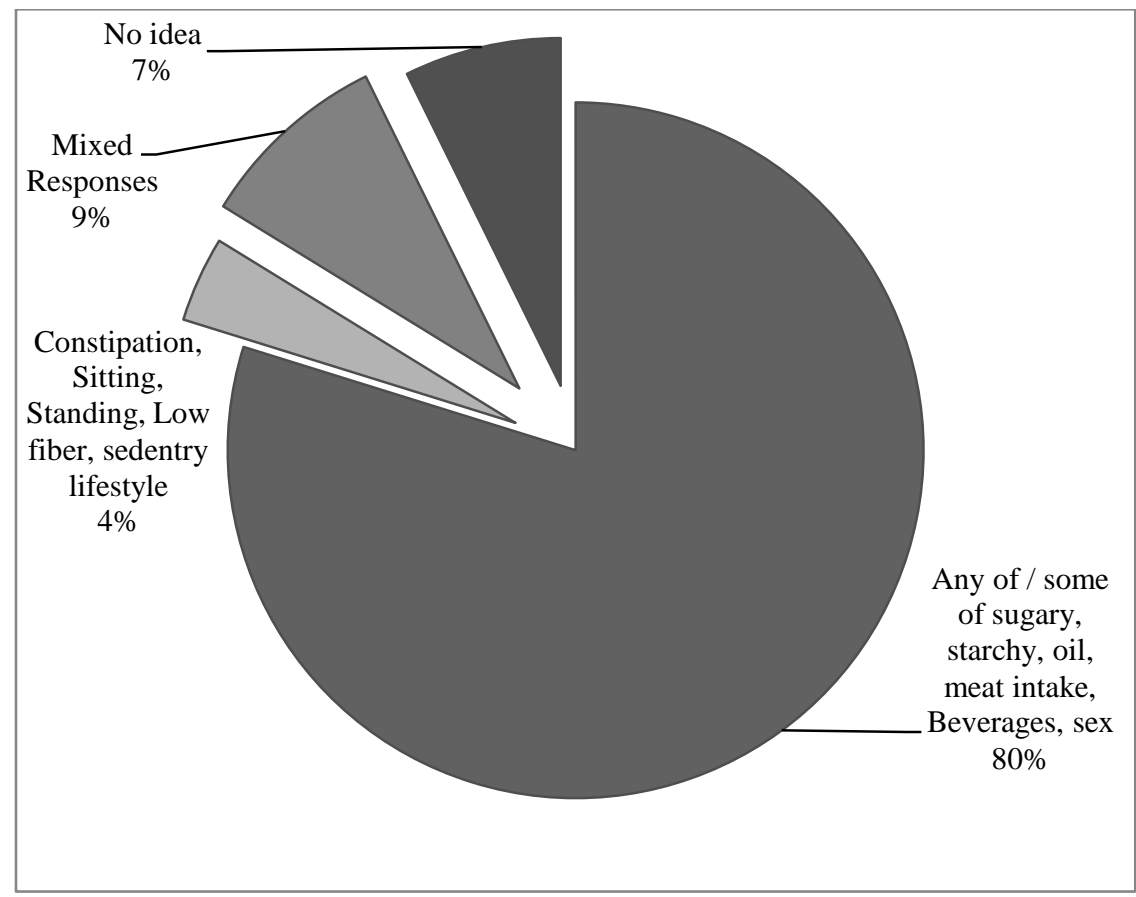

Figure 1: Level of Awareness of the Causes of Piles 
However, all the medical doctors interviewed held opinions that were contrary to the popularly held misconceptions expressed by the officers and herbal vendors. The comment below comprehensively summarized the position of the medical practitioners on causes of hemorrhoids:

The risk factors of hemorrhoids are very many especially during pregnancy. Nutritional factor such as low fiber diet can predispose individuals to hemorrhoids. So also, those who are used to straining, straining when passing stool and urine, are at risk of the disease. Coughing for a long-time (chronic) beyond two weeks can lead to hemorrhoid. Obesity is another risk factor; people that are obese are prone to it. People who sit for a long-time or who lead a sedentary lifestyle are susceptible to hemorrhoids. (KII.a, male medical practitioner, Eleyele, Ibadan)

From the available literature, little has been done to clarify the relationship that exists between sugar and piles. Olateju (2009) only explained how herbal vendors cajole their unsuspecting customers with the idea but he did not draw a relationship between sugar intake and piles. The medical doctors interviewed asserted that intake of sugar had no scientific proof to support that it is a risk factor for hemorrhoids. However, they stated that it can only aggravate bleeding by retarding the healing process because bacteria thrive on sugary surface.

Undoubtedly, the majority of the respondents believed that sugary intake predisposes individuals to piles. This confirms that many people do not usually consult medical doctors during the illness, because if they did, they would be aware of hemorrhoids' risk factors. In previous studies, Pelto and Gretel (1990) and Jegede (2002) found that illness is culturally defined. As a result, people tend to evaluate their health status and explain their present health challenges based on accumulated cultural knowledge. This implies that a large majority may continue to suffer from the recurrence of piles.

\section{Perceived Effects of Hemorrhoids}

Table 2 presents respondents' perception about the effects of hemorrhoids on sexual relations and work. Sexual relations in this context connote the ability to perform effectively during sexual activities. Analysis of responses to the statement questions raised revealed that respondents accepted (aggregate score of 4.3 for male and 4 for female) that piles impede sexual relations. It is evident that more male police officers agreed that hemorrhoids hinder sexual activity than their female counterparts ( $91.6 \%$ of males and $76.7 \%$ of females). Consequentially, an associational test ( $p$ $<.05$ ) suggests that there is a significant relationship between officers' sex and their perception as regards effects of piles on sexual relation. Similarly, all the herbal vendors upheld subjective effects of hemorrhoids, which were vividly described by one of them as follows:

...it is common among young men because piles can negatively affect their manhood... Some women expecting menstruation may complain of backache. Then such woman should take Jedi drink. The drug is also good for women who complain of menstrual abdominal pain or backache...especially in married men, who used to have many rounds of sexual escapade and could not do that again. They would have known that piles has come. Or he gets to a woman and cannot perform. He would have known that the piles is around. In female folks, piles can seize their menstrual cycle, make them unable to sit... Piles can prevent work, if one gets to workplace but cannot sit or stand and remains uncomfortable. (KII.e, female herbal vendor, Oyo) 
The findings from the police officers and the herbal vendors revealed cultural beliefs about hemorrhoids that have no empirical proofs. This affects the kind of herbal remedy for piles.

Table 2: Officers' Perceptions About Effect of Hemorrhoid on Sexual Activities and Work

\begin{tabular}{|c|c|c|c|c|c|c|}
\hline $\begin{array}{l}\text { Statement of } \\
\text { Officers' } \\
\text { Perceptions }\end{array}$ & $\begin{array}{c}\text { Strongly } \\
\text { Agree }\end{array}$ & Agree & Indifferent & Disagree & $\begin{array}{l}\text { Strongly } \\
\text { Disagree }\end{array}$ & $\begin{array}{l}\text { Mean } \\
\text { Score }\end{array}$ \\
\hline \multicolumn{7}{|c|}{ "Piles affect sexual relation negatively." } \\
\hline Male & $92(45.3 \%)$ & $94(46.3 \%)$ & $7(3.5 \%)$ & $3(1.4 \%)$ & $7(3.5 \%)$ & 4.3 \\
\hline Female & $44(44.4 \%)$ & $32(32.3 \%)$ & $11(11.1 \%)$ & $7(7.1 \%)$ & $5(5.1 \%)$ & 4 \\
\hline \multicolumn{7}{|c|}{ "Piles affect work negatively." } \\
\hline Male & $43(21.2 \%)$ & $109(53.7 \%)$ & $13(6.4 \%)$ & $21(10.3 \%)$ & $17(8.4 \%)$ & 3.7 \\
\hline Female & $15(15.1 \%)$ & $44(44.4 \%)$ & $17(8.4 \%)$ & $13(13.1 \%)$ & $10(10.1 \%)$ & 3.4 \\
\hline
\end{tabular}

The Table 2 further presents the outcome of the test of association between the sex of officers and their perception about the effect of piles on their work. This associational test $(p<.05)$ reveals that there is a significant relationship between sex of officers and their perception about the adverse effect of piles on work. Accordingly, the mean score of 3.7 depicts that more male officers submitted that piles affected work adversely compared to their female counterparts with the mean score of 3.4. About $75 \%$ of male police officers and $59.5 \%$ of females agreed that piles hinder work performance. Moreover, multiple symptoms for piles were identified by the respondents including sexual problems (such as weak erection, early ejaculation during sex, reduction in the size of manhood, and impotence tendency), backache, waist pain, stooling, difficulty in stooling, blood-stained stool, inability to sit or stand for long time, and stomach upset and pain, and painful menstruation and poor libido in women.

Therefore, what the respondents considered the symptoms of the illness included the symptoms of other diseases. As a result, some of the respondents were suffering from some other diseases without even knowing. As noted in the study, this lack of awareness cuts across all demographic characteristics of the respondents, since the majority of respondents gave multiple symptoms to describe piles. This probably explains further other dimensions of misconception about hemorrhoids. Similarly, hemorrhoids hinder more male police respondents than female group from discharging their duties. Consequently, piles preclude officers from performing their expected social roles.

\section{Management and Treatments of Hemorrhoids}

This study reveals the result of a test of association between the type of treatment officers could afford and use of herbal treatment among them. The associational test $(p<.05)$ reveals that there is a significant relationship between affordability of a treatment and use of herbal treatment for piles among police officers. This shows the participants' rationales for their choice of treatment for piles. Hence, the affordability of a treatment is one of the major factors that determine choice of therapy. The study further presents the influence of religion on the usage of herbal medicine among police respondents. This indicates that a large majority (92\%) of the Christian police respondents and more than $97 \%$ of the Muslim police respondents used herbal treatment for piles. Predictably, all respondents who practiced traditional religion used herbal medicine. Consequentially, the associational test $(p>.05)$ confirmed that there is no significant relationship between religion of the officers and the use of herbal therapy. Therefore, this suggests that religion does not influence the use of herbal medicine among patients. 
Figure 2 displays how respondents managed hemorrhoids during hemorrhoidal episode. One third (34\%) of the respondents adopted the reduction of sugar, carbohydrates, starches, and beverages as the treatment during hemorrhoidal episode. This is followed by one fifth (24\%) of the respondents who did nothing when they had piles. Some of the respondents used home treatment. Fewer than one fifth (15\%) of the respondents opted for herbs (scent leaves) and more than a tenth (11\%) used drugs, took medical advice, and had a check-up; $2 \%$ adopted both types of home treatments. Equally, $2 \%$ of the respondents endured and engaged in prayer during piles episodes.

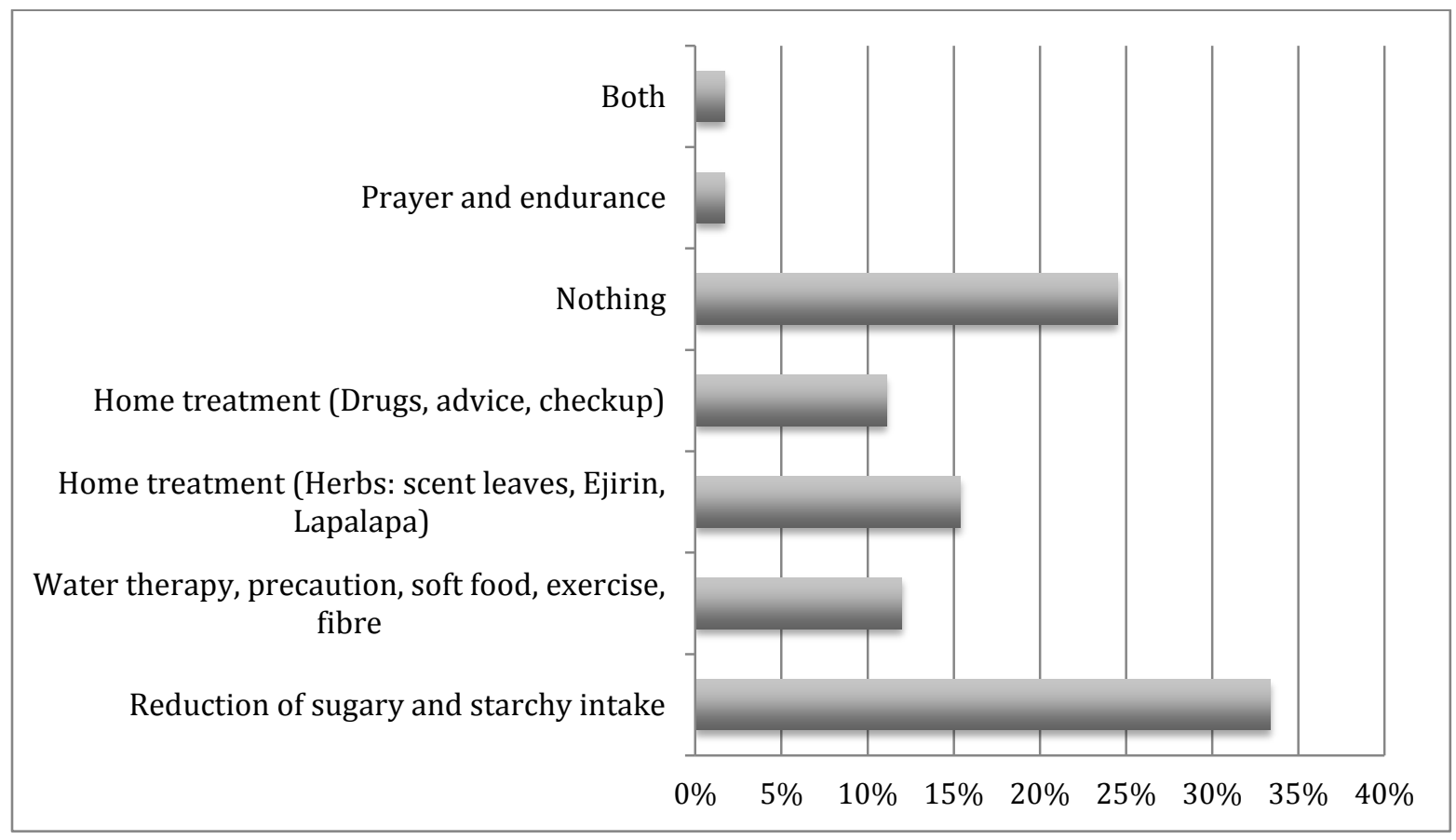

Figure 2: Management Approaches Used During Hemorrhoidal Episode

In the thematic analysis of all medical practitioners' responses, similar patients' choice of health pathways during hemorrhoidal episode was established in their discussion. The majority of the patients would resort to home treatment and avoid sugary and starch substances. The following excerpt presents the comprehensive view of the medical practitioners on treatment pathway of patients.

This conclusion is based on what we have heard from them. What is so much common in this region, everybody must have tried one thing at home, which is not exclusive to hemorrhoids: "home remedies," "self-medication," "maybe this thing will work," or "let me try that one." Based on the report we heard from them, some have consulted for remedies, herbal vendors who would tell them to get some herbs such as scent leaves etc. squeeze it, extract its liquid and drink it. Some exposed their anus to hot flames or liquid as a way of controlling ailment because it starts gradually. Some are encouraged to observe personal hygiene because of the itching around anus. Some keep trying until it becomes unbearable. (KII.b, male medical practitioner, Ogbomoso) 
Above all, the majority of the respondents would have developed and adopted at least one management style. However, a few of the respondents did not use any therapy before visiting either herbal vendors or medical practitioners.

Table 3 presents the respondents' choice of therapies during hemorrhoidal episode. Close to two thirds $(61 \%)$ of the respondents reportedly used herbal therapy to treat the illness, followed by more than one quarter $(30.2 \%)$ who reportedly used both herbal and modern treatment when they had piles. Thus, the majority of the respondents patronized local herbs for the treatment of piles.

Table 3: Distribution of Respondents by Type of Treatment Used During Hemorrhoidal Episode

\begin{tabular}{lcc}
\hline Treatments for Piles & Frequency & Percent \\
\hline Herbal treatment & 135 & 60.8 \\
Modern treatment & 17 & 7.7 \\
Both treatments & 67 & 30.2 \\
None & 3 & 1.0 \\
Total & 222 & 100 \\
\hline
\end{tabular}

Also, both medical practitioners and herbal vendors agreed that there is high patronage for herbal treatment for piles. This is similar to the officers' reports presented in Table 3. The following responses capture the people's choice of therapy during hemorrhoidal episode.

...you see we have to be sincere with ourselves, because as soon as we encounter one patient like this, the condition would have escalated and you ask why they were just coming to the hospital. Because by now you were supposed to have noticed it for some time, they would try to cover-up but we got to know that they have visited one local practitioner. (KIIa, male medical personnel, Ogbomoso)

One of the herbal vendors also said,

People consume herbal medicine more than the modern medicine. If one says he has gone to buy metronidazole, it does not really work. What I know metronidazole for is when one is stooling and wants a stop to it. If one is having difficulty defecating, they cannot give any drug from the chemist but we can give them herbal drink or powder which will aid defecation. (KII.c, female herbal vendor, Agbowo Ibadan)

Indeed, such affirmations suggest that the majority of people with hemorrhoids use herbal treatment for piles and this may suggests that herbal medicine is perceived to be more effectiveness in the treatment of piles. 


\section{Discussion}

The study examined the sociocultural determinants of choice of hemorrhoid therapy among the police officers and sought to identify cultural misconceptions about hemorrhoids. The working assumption was that the information that an individual had about hemorrhoids would affect his or her health-seeking behaviors, preventive measures, and treatments used during hemorrhoidal episodes. This study found that there was a high prevalence of hemorrhoids among police officers, especially among female police officers. The study further indicated that more than $76 \%$ of female officers compared to $71.9 \%$ of male officers had had piles. Similarly, other studies have found that the prevalence of hemorrhoids was higher among women, especially during pregnancy, compared with men (Alonso \& Castillejo, 2003; Kaidar-Person et al, 2007).

Furthermore, previous studies revealed that the factors, which predisposed individuals to piles, include constipation, anal sex, and obesity. This study identified the misconceptions stated in the previous studies (Alatise et al, 2010; Lohsiriwat, 2015) about the factors responsible for piles, as the majority of the respondents argued that sugary and starchy intakes, meat, beverages, etc. cause hemorrhoids (see Figure 1). More than three quarters (80\%) of the respondents upheld these misconceptions. This high level of misconception informed by indigenous knowledge influences the cultural definition of piles. As noted in the study, herbal vendors upheld the same misconception about piles. Equally, Pelto and Gretel (1990) and Jegede (2002) found that illness is culturally defined, whereas Lohsiriwat (2012) maintained that there were philosophies in the etiology of hemorrhoids. As a result, people tend to evaluate their health status and explain their present health challenges based on accumulated cultural knowledge. In effect, large majority may continue to suffer from the recurrence of piles.

Contrary to the symptoms of hemorrhoids identified in previous studies (Hemorrhoid Institute of South Texas, 2009; Pare, Ferrazzi, Thompson, Irvine, \& Rance, 2001; World Gastroenterology Organisation, 2007), respondents in the current study reported multiple symptoms of piles. The symptoms included sexual problems (including weak erection in men, early ejaculation during sex, reduction in the size of manhood, and impotence tendency), backache, waist pain, stooling, stomach upset and pain, as well as painful menstruation and poor libido in women. Specifically, the majority (91\%) of the male respondents and $76.7 \%$ of the female respondents stated that piles preclude their sexual relations. In addition, the majority ( $86.1 \%$ male and $84.9 \%$ female) of the respondents reportedly believed that piles could cause backache and eventually affect work. The opinions of the respondents about the symptoms of the illness cover the symptoms of other diseases, thus further explaining other dimensions of poor knowledge about hemorrhoids (Lohsiriwat, 2015).

As argued by Lohsiriwat (2012), hemorrhoids constitute a burden socioeconomically. Confirming this position, close to three fourths (70\%) of the respondents affirmed that piles affected their work negatively. Furthermore, $72 \%$ of male and $66 \%$ of female respondents advised that patients suffering from pile should consult a doctor, as hemorrhoids affect the quality of life (Sun \& Migaly, 2016). However, the majority ( $82 \%$ male and $70 \%$ female) of the respondents preferred traditional treatments during their piles episodes. The respondents would opt for the treatment they could afford. For instance, $77 \%$ of male and $70 \%$ of female respondents could afford only traditional therapies. Previous studies established that there is a high level of patronage for herbal medicine (Osungunna et al., 2010) and recommended herbal medicine for patient as a result of its cost effectiveness (Li, Chang, Hsu, Lu, \& Fang, 2013; World Health Organization, 2003). Consequently, this finding indicates that preference for traditional medicine to treat piles was based on its affordability. 
Moreover, available literature has not adequately clarified if there is a causal relationship that exists between sugar intake and piles. Olateju (2009) only explained how herbal vendors promote the view among unsuspecting customers but he did not draw a causal relationship between sugar intake and hemorrhoids. The medical doctors interviewed, asserted that there was no scientific proof to support that sugary intake constitutes a risk factor for hemorrhoids but that it can only aggravate anal bleeding. As noted in the study, herbal vendors asserted that physicians treat symptoms of hemorrhoids only but herbal medicine goes to the source of hemorrhoids. In other words, herbal vendors believe that there are inadequacies in the orthodox treatments and procedures for piles. Likewise, Vladimir et al. (2015) and Morelli (2015) maintained that treatment of hemorrhoidal disease is complex, and Cleator and Cleator (2010) found that the treatment of hemorrhoids is often unsatisfactory due to recurrence or complication.

Previous studies have identified different treatments and procedures for piles but only very few respondents know more than the conventional medicine (hemorrhoidectomy) and herbal treatments (herbal drinks and powder). Previous studies on modern treatments for hemorrhoid have identified the therapies available to hemorrhoidal patients (Feldstein \& Kay, n.d.; Giamundo et al., 2011; Halverson, 2007; Lohsiriwat, 2015). In addition, all of the herbal vendors stated that there is a special powder that patients with protruding internal hemorrhoids can apply after defecation for it to retract. This suggests that many of the respondents do not make the necessary enquiries about the other available therapies and procedures. Probably, the respondents have not received sufficient information about piles management, because the associational test depicts that there is a significant relationship between the fear of hemorrhoidectomy and unprecedented patronage for Jedijedi herbal treatment among police officers.

It is revealed in the present study that more than half (60.8\%) of the respondents reportedly used herbal medicine for piles, although excisional hemorrhoidectomy remained the mainstay operation for advanced and complicated hemorrhoids (Lohsiriwat, 2015). Previous studies have indicated that modern treatments are safe (LaBella, Main, \& Hussain, 2015) and more effective than the traditional surgery for circumferential hemorrhoids (Ming, Bo, Yang, Qing, \& Hao 2015). Contrary to previous studies by Teshome-Bahiru (2004) and Jegede (2010), this study found that despite the fact that the majority of the respondents perceived piles as natural disease, $60.8 \%$ reportedly patronized herbal vendors during illness episodes. The finding suggests that officers' beliefs may have influenced their choice of therapy.

The present study revealed the general cultural misconception about piles among police officers and the herbal vendors who claimed expertise in the treatment of the disease. This is in tandem with Olateju's (2009) finding. However, the modern medical doctors interviewed did not support the herbal vendors' explanation on the risk factors. Previous medical studies on hemorrhoids corroborate the physicians' explanation (Lohsiriwat, 2015, Omole \& Adegboye, 2012). To address the misconceptions, Siegel and Di Palma (2005) suggested that patients should be educated on bowel movements. All the herbal vendors interviewed maintained that sugar causes piles. Olateju (2009) only explained how herbal vendors advertise their herbal remedies for piles without establishing a causal relationship between sugar intake and piles. Also, herbal vendors believe the subjective effects of hemorrhoids reported by majority of the police officers. This was contrary to medical doctors' orientation about the disease. For hemorrhoid management, Osungunna et al. (2010) reported high patronage for piles herbal medicine, and both orthodox medicine practitioners and herbal vendors confirmed this. However, there was a disagreement between medicine practitioners and herbal vendors over the effects of the disease, as herbal vendors reported a relationship between piles and sexual strength. 


\section{Limitation of the Study}

A limitation of the current study is that one of the proposed respondents for a key informant interview could not be interviewed. In addition, there exist limited previous studies on hemorrhoids, which have been conducted from cultural perspectives. This study used nonrandom sampling techniques among the study population; thus, the findings might not be generalized to other populations.

\section{Conclusion}

Misconceptions about hemorrhoids - such as the belief that sugar is one of its risk factors and that hemorrhoids preclude sexual activities-are pervasive among the Nigeria Police Force officers and herbal vendors. These misconceptions are evident in the reported associated causes, symptoms, and perceived effects, all of which affect health-seeking behaviors. This low level of awareness necessitates the need for comprehensive and objective understanding of piles among the officers and the herbal vendors that treat the disease. Therefore, it is recommended that more studies should be conducted on hemorrhoids and the populace should be enlightened via mass media to adopt healthier practices. In addition, a collaborative platform should be established for both herbal practitioners and modern practitioners to synergize to combat misconceptions about hemorrhoids.

\section{References}

Alatise, O. I., Agbakwuru, A. E., Takure A. O., Adisa A. O., \& Akinkuolie A. A. (2010). Open hemorrhoidectomy under local anesthesia for symptomatic hemorrhoids: Our experience in Ile-Ife, Nigeria. African Journal of Health Science, 17, 42-46.

Alonso, P., \& Castillejo, M. M. (2003). Phlebotonics for hemorrhoids. Cochrane Database of Systematic Reviews, 1, 004322.

Cleator, I. G. M., \& Cleator, M. M. (2010). The long-term results of hemorrhoids band using the O’Regan disposable suction liga. Vancouver, Canada: Scott Morrison Investments.

Department of Public Safety Standards and Training. (2011). Medical examination for police, corrections and parole \& probation officers (DPSST Form F-2). Retrieved January 1, 2013, from www.oregon.gov/DPSST/Pages/index.aspx

Erinosho, O. A. (1998). Health sociology. Ibadan, Nigeria: Sam Bookman Educational and Communication Services.

Federal Ministry of Health. (2008). Standard treatment guidelines: Nigeria 2008. Retrieved from http://www.health.gov.ng/doc/StandardTreatmentGuidelines.pdf

Feldstein, A. E., \& Kay, M. H. (n.d.). Hemorrhoids. Retrieved from https://www.gastroconsa.com/patient-education/hemorrhoids/

Giamundo, P., Sali, R., Geraci, M., Tibaldi, L., Muru, L., \& Valente, M. (2011). The hemorrhoid laser procedure technique vs. rubber band ligation: A randomized trial comparing 2 mini-invasive treatments for second- and third-degree hemorrhoids. Disease of the Colon and Rectum, 54, 693-698.

Gureje, O., Lasebikan, V. O., Olusola, E., Benjamin, O. O., \& Lola, K. (2005). Community study of knowledge of and attitude to mental illness in Nigeria. British Journal of Psychiatry, 186, $436-441$.

Halverson, A. (2007). Hemorrhoids. Clinical Colon Rectal Surgery, 20, 77-85. 
Hemorrhoid Institute of South Texas. (2009). Hemorrhoids summary. Retrieved from https://www.scribd.com/document/285957127/hemorrhoidsummary-pdf

Jegede, A. S. (2002). The Yoruba cultural construction of health and illness. Nordic Journal of African Studies, 11, 322-335

Jegede, A. S. (2010). African culture and health. Ibadan, Nigeria: Book Wright Publishers.

Kaidar-Person, O., Benjamin, P., M. D., \& Steven, D. W. (2007). Hemorrhoidal disease: A comprehensive review. Collective Reviews, 204, 102-117.

Kish, L. (1965). Survey sampling. New York, NY: Wiley.

LaBella, G. D., Main, W. P. L., \& Hussain, L. R. (2015). Evaluation of transanal hemorrhoidal dearterialization: A single surgeon experience. Techniques in Coloproctology, 19, 153-157.

Lee, J. H., Kim, H. E., Kang, J. H., Shin, J. Y., \& Song, Y. M. (2014). Factors associated with hemorrhoids in Korean adults: Korean National Health and Nutrition Examination Survey. Korean Journal of Family Medicine, 35, 227-236.

Li, C., Chang, Y., Hsu, C., Lu, R. J., \& Fang, H. (2013). Joint predictability of health-related quality of life and leisure time physical activity on mortality risk in people with diabetes. $B M C$ Public Health, 13, 67.

Lohsiriwat, V. (2012). Hemorrhoids: From basic pathophysiology to clinical management. World Journal of Gastroenterology, 18, 2009-2017.

Lohsiriwat, V. (2013). Approach to hemorrhoids. Current Gastroenterology Reports, 15, 332.

Lohsiriwat, V. (2015). Treatment of hemorrhoids: A coloproctologist's view. World Journal of Gastroenterology, 21, 9245-9252.

Ming, L., Bo, Y., Yang, L., Qing, L., \& Hao, W. (2015). Procedure for prolapse and hemorrhoids vs traditional surgery for outlet obstructive constipation. World Journal of Gastroenterology, 21, 8178-8183.

Morelli. U. (2015). Hemorrhoidal disease, from legacy to a change of perspective. International Journal of Gastroenterology Disorder Therapy, 2, 112. doi:10.15344/2393-8498/2015/112

Olateju, A. (2009). Jedi O M'Akowe (Hemorrhoid respects not even the educated elite): A sociolinguistic-stylistic analysis of the language of Yoruba herbal medicine practitioners. In A. Ojo \& L. Moshi (Eds.), Selected proceedings of the 39th Annual Conference on African Linguistics (pp. 156-165). Somerville, MA: Cascadilla Proceedings Project.

Omole, M. K., \& Adegboye, O. O. (2012). A ten year study of the management of hemorrhoids at a secondary nursing home in south west Nigeria. International Research Journal of Pharmacy, 3, 198-200.

Osungunna, M. O., Oluremi, B. B., \& Talabi, I. (2010). Comparative microbial quality of Jedi drinks sold in two major cities in Nigeria. Pakistan Journal of Nutrition. 9, 769-772.

Pare, P., Ferrazzi, S., Thompson, W. G., Irvine, E. J., \& Rance, L. (2001). An epidemiological survey of constipation in Canada: Definitions, rates, demographics, and predictors of health care seeking. American Journal of Gastroenterology, 96, 3130-3137.

Pelto, P. J., \& Gretel, H. P. (1990). Field methods in medical anthropology. In T. N. Johnson \& C. F. Sargent (Eds.), Medical anthropology: Contemporary theory and method (pp. 269-297). New York, NY: Praeger. 
Siegel, J. D., \& Di Palma, J. A. (2005). Constipation and Functional bowel disease: Medical treatment of constipation. Clinical Colon Rectal Surgery, 18, 76-80.

Soladoye, M. O., Chukwuma, E. C., \& Owa, F. P. (2012). An "avalanche" of plant species for the traditional cure of diabetes mellitus in south-western Nigeria. Journal of Natural Product and Plant Resources, 2, 60-72.

Sun, Z., \& Migaly, J. (2016). Review of hemorrhoid disease: Presentation and management. Clinical Colon Rectal Surgery, 29, 22-29.

Teshome-Bahiru, W. (2004). Concept of health, disease, illness and therapy among the people of Addis Ababa. Annals of African Medicine, 3, 28-31.

Vladimir, C., Milena, S., Igor, K., Marko, K., Bojan, K., \& Vladica C. (2015). Where are we now in the treatment of hemorrhoids. Acta Medica Medianae, 54, 95-106.

Weber, M. (1991). The nature of social action. In W. G. Runciman (Ed.), Weber: Selections in translation (pp. 492-518). Cambridge, United Kingdom: Cambridge University Press.

World Gastroenterology Organisation. (2007). WGO practice guideline: Constipation. Retrieved from http://www.worldgastroenterology.org/guidelines/global-guidelines/constipation

World Health Organization. (2003). WHO guidelines on good agricultural and collection practices $(G A C P)$ for medicinal plants. Geneva, Switzerland: Author.

The Journal of Social, Behavioral, and Health Sciences is an open-access, peer-reviewed, online interdisciplinary journal focusing on research findings that address contemporary national and international issues. Its objectives are to (a) encourage dialogue between scholars and practitioners in the social, behavioral, and health sciences that fosters the integration of research with practice; (b) promote innovative models of interdisciplinary collaboration among the social, behavioral, and health sciences that address complex social problems; and (c) inform the relationship between practice and research in the social, behavioral, and health sciences.

Walden University Publishing: http://www.publishing.waldenu.edu 